\title{
Anagostic Interactions under Pressure: Attractive or Repulsive?
}

\section{Wolfgang Scherer *[a], Andrew C. Dunbar ${ }^{[a]}$, José E. Barquera-Lozada ${ }^{[a]}$, Dominik Schmitz ${ }^{[a]}$, Georg Eickerling ${ }^{[a]}$, Daniel Kratzert ${ }^{[b]}$, Dietmar Stalke ${ }^{[b]}$, Arianna Lanza ${ }^{[c, d]}$, Piero Macchi*c], Nicola P. M. Casati ${ }^{[d]}$, Jihaan Ebad-Allah ${ }^{[a]}$ and Christine Kuntscher ${ }^{[a]}$}

The term "anagostic interactions" was coined in 1990 by Lippard and coworkers to distinguish sterically enforced $M \cdot \bullet \cdot \mathrm{H}-\mathrm{C}$ contacts ( $M=\mathrm{Pd}, \mathrm{Pt})$ in square-planar transition metal $\mathrm{d}^{8}$ complexes from attractive, agostic interactions. ${ }^{[1 a]}$ This classification raised the fundamental question whether axial $M \bullet \bullet H-C$ interaction in planar $\mathrm{d}^{8}-M L_{4}$ complexes represent (i) repulsive anagostic 3c-4e $M \cdots \cdot \mathrm{H}-\mathrm{C}$ interactions $^{[1]}$ (Scheme 1a) or (ii) attractive 3c-4e $M \cdots \cdot \mathrm{H}-\mathrm{C}$ hydrogen bonds ${ }^{[2]}$ (Scheme 1b) in which the transition metal plays the role of a hydrogen-bond acceptor (Scheme 1b). The latter bonding description is related to another bonding concept which describes these $M \cdot \bullet \cdot \mathrm{H}-\mathrm{C}$ contacts in terms of (iii) pregostic or preagostic interactions ${ }^{[3]}$ (Scheme 1c) which are considered as being "on the way to becoming agostic, or agostic of the weak type". ${ }^{[4]}$

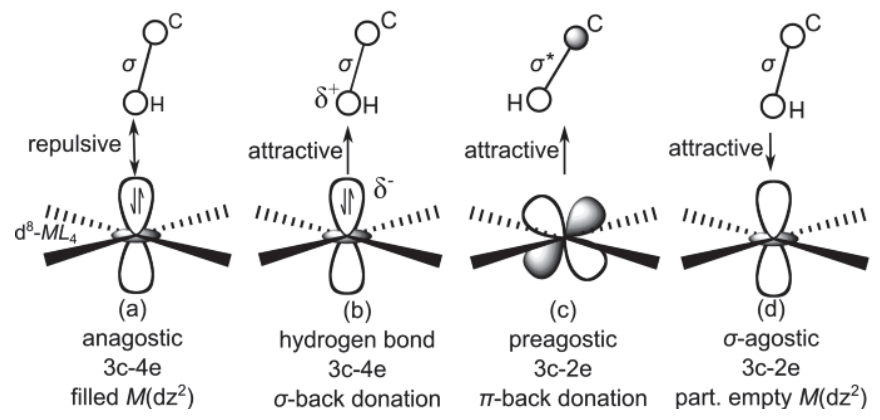

Scheme 1.

In contrast to the first two types of interactions which require the presence of a fully occupied and axially oriented $M\left(\mathrm{~d}_{z}^{2}\right)$ orbital,

[*][a] Prof. Dr. W. Scherer, Dr. A. C. Dunbar, Dr. J. E. BarqueraLozada, MSc. D. Schmitz, Dr. G. Eickerling, Dr. J. E. EbadAllah, Prof. Dr. Ch. Kuntscher

Institut für Physik

Universität Augsburg

86135 Augsburg (Germany)

Fax: (+49)821-598-3227

E-mail: wolfgang.scherer@physik.uni-augsburg.de

[b] Prof. Dr. D. Stalke, Dr. D. Kratzert Institut für Anorganische Chemie

Georg-August-Universität Göttingen

Tammannstraße 4, 37077 Göttingen (Germany)

[*][c] PD Dr. P. Macchi, A. Lanza

Department of Chemistry \& Biochemistry University of Berne

Freiestrasse 3, $\mathrm{CH}-3012$ Berne (Switzerland)

Fax: (+41)31-631-4281

E-mail: piero.macchi@dcb.unibe.ch

[d] Dr. N. P. M. Casati, A. Lanza

Paul Scherrer Institut

WLGA/229, CH-5232 Villigen PSI (Switzerland)

[**] This work was supported by the DFG (SPP1178) project number SCHE478/12-1 and the SNSF project Nr. 144534. preagostic interactions are considered to lack any "involvement of $d z^{2}$ orbitals in $M \cdots \cdot H-C$ interactions" and rely mainly on $M\left(\mathrm{~d}_{\mathrm{xz}, \mathrm{yz}}\right)$ $\rightarrow \sigma *(\mathrm{C}-\mathrm{H}) \pi$-back donation. ${ }^{[3 \mathrm{~b}]}$

The first observation of unusual axial $M \bullet \bullet \mathrm{H}-\mathrm{C}$ interaction in planar $\mathrm{d}^{8}-M L_{4}$ complexes was made by $\mathrm{S}$. Trofimenko, who pioneered the chemistry of transition metal pyrazolylborato complexes. ${ }^{[5,6]}$ Trofimenko also realized in 1968, on the basis of NMR studies, that the shift of the pseudo axial methylene protons in the agostic species $\left[\mathrm{Mo}\left\{\mathrm{Et}_{2} \mathrm{~B}(\mathrm{pz})_{2}\right\}\left(\eta^{3}\right.\right.$-allyl $\left.)(\mathrm{CO})_{2}\right]$ (1) $(\mathrm{pz}=$ pyrazolyl; allyl $=\mathrm{H}_{2} \mathrm{CCHCH}_{2}$ ) "is comparable in magnitude but different in direction from that observed in $\mathrm{Ni}\left[\mathrm{Et}_{2} \mathrm{~B}(\mathrm{pz})_{2}\right]_{2}$ " (2) (Scheme 2). ${ }^{[6,7]}$

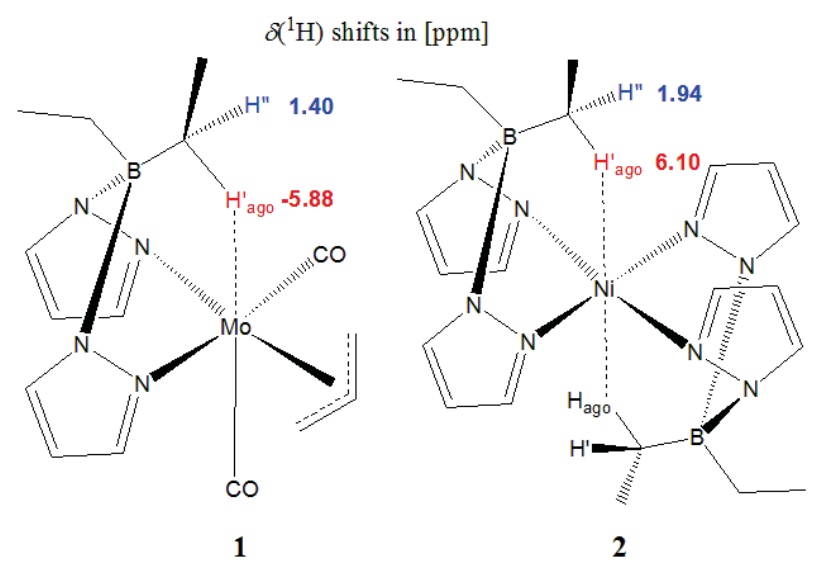

Scheme 2.

Indeed, the protons of the methylene group which form a close $M \bullet \bullet C$ contact of $[2.954(2) \AA]^{[8]}$ in 1 resonate at -2.41 ppm at RT, ${ }^{[9]}$ while the corresponding signal of the methylene protons of $\mathbf{2}$ occurs at $3.64 \mathrm{ppm}\left(q, \mathrm{CH}_{2},{ }^{2} J_{\mathrm{H}-\mathrm{H}} 8 \mathrm{~Hz}\right)$ and does not show any coalescence upon cooling to $-90^{\circ} \mathrm{C}$ despite large differences in the calculated chemical shifts ${ }^{[10 \mathrm{a}]}$ of both methylene protons (Scheme 2). In contrast, the ${ }^{1} \mathrm{H}$ NMR signal of the agostic methylene protons in $\mathbf{1}$ splits into two features $(-0.83$ and -4.3$)$ below $-53^{\circ} \mathrm{C}^{[9]}$ in agreement with the computed NMR properties of our static DFT model (1.4 and $-5.88 \mathrm{ppm}$ ) for the agostic $\mathrm{Mo} \cdots \mathrm{H}_{\mathrm{ago}}-\mathrm{C}$ and non-coordinating methylene proton, respectively (Scheme 2). Trofimenko concluded that the agostic proton in $\mathbf{1}$ displays a "hydridic" character and that the agostic proton of $\mathbf{1}$ is "intruding into a suitable empty metal orbital." ${ }^{[6 a]} \mathrm{He}$, therefore, suggested that the $\mathrm{M} \bullet \bullet \mathrm{H}-\mathrm{C}$ interactions in $\mathbf{1}$ is a bonding one causing an activation of the $\mathrm{C}-\mathrm{H}$ bonds as evident by the "presence of $\mathrm{CH}$ stretch bands at remarkably low frequency" of $2704 \mathrm{~cm}^{-1}$.6b] This concept was later developed and refined by Brookhart and Green (BG); who coined the expression "agostic" for these kind of interactions. ${ }^{[11]}$ According to the original criteria of $\mathrm{BG}$, agostic interactions would be present in $\mathbf{1}$ but clearly absent in 2 since the latter compound displays a pronounced $\delta\left({ }^{1} \mathrm{H}\right)$ down-field shift in the case of the $\mathrm{Ni} \bullet \bullet \mathrm{H}-\mathrm{C}$ coordinating methylene protons. This conclusion is also in accord with the structural study of $\mathbf{2}$ by 
Echols and Dennis in 1974 who concluded that "steric restrictions dictate the conformation of the molecule, not an interaction of $\mathrm{Ni}$ with an apical $H$ atom" of one of the methylene groups of the pyrazolylborato ligand. ${ }^{[1 b, 12]}$ A subsequent Extended Hückel Theory (EHT) study by Saillard and Hoffmann $(\mathrm{SH})^{[1 \mathrm{c}]}$ gave further evidence that the interaction between an axially approaching $\mathrm{H}-\mathrm{C}$ ligand (e.g. $\mathrm{CH}_{4}$ ) and the $\mathrm{d}^{8}-M L_{4}$ metal fragment might be actually even repulsive due to the presence of a fully occupied and axially oriented $(M) \mathrm{d}_{\mathrm{z}}{ }^{2}$-orbital (Scheme 1a). ${ }^{[1 \mathrm{c}]}$ However, the nature of these $\mathrm{d}^{8}-\mathrm{M} \bullet \cdot \mathrm{H}-\mathrm{C}$ interactions and their description in terms of either (i) anagostic interactions, (ii) hydrogen-bonds, or (iii) pregostic interactions remains an ongoing matter of debate. ${ }^{[13]}$ We will therefore outline in the following that all three bonding concepts ( $i$ iii; Scheme 1) basically rely upon an oversimplified description of the electronic situation in $\mathrm{d}^{8}-M L_{4}$ complexes, which causes a misinterpretation of the fundamental $\mathrm{C}-\mathrm{H}$ bond activation processes in these types of compounds. ${ }^{[13 c]}$

We first reanalyze the potential energy surface (PES) of the $\sigma$ model complex $\left[\mathrm{Co}(\mathrm{CO})_{4}^{+}\right] \cdot\left[\mathrm{CH}_{4}\right]$ (3) formed by methane and the positively charged $\mathrm{d}^{8}-\left[M L_{4}\right]^{+}$metal fragment. In line with SH's findings ${ }^{[3]}$ (see above), the EHT-PES predicts a repulsive 3c-4e $M \bullet \bullet \mathrm{H}-\mathrm{C}$ interaction in the methane adduct $\mathbf{3}$, which was selected by BS as benchmark model. In these model calculations one C-H moiety of the methane molecule was geometrically enforced to approach the square-planar $\mathrm{d}^{8}-\left[M L_{4}\right]^{+}$metal fragment in an axial coordination mode (Supporting Information S2). However, considering electronic correlation effects via DFT methods reveals in contrast to the EHT results the actually attractive nature of the $M \bullet \bullet-\mathrm{C}$ interaction in this $\mathrm{d}^{8}-M L_{4}$ benchmark system (Figure S2a,b). The electronic situation of $\mathbf{3}$ is therefore characteristic for a $\mathrm{H}_{3} \mathrm{C}-\mathrm{H} \cdots M L_{4}$ sigma complex, which at an early stage of the oxidative addition reaction coordinate exhibits a modest $\mathrm{C}-\mathrm{H}$ activation due to a covalent interaction between an occupied $\sigma(\mathrm{C}-\mathrm{H})$ orbital and a vacant metal orbital (Scheme 1d).

Motivated by this result, we continue to reanalyze the electronic situation in 2 - as a benchmark system of an uncharged $d^{8}-M L_{4}$ complex displaying an axial $M \bullet \bullet \mathrm{H}-\mathrm{C}$ interaction. In the presence of a $M\left(\mathrm{~d}_{\mathrm{z}}^{2}\right) \leftarrow \sigma(\mathrm{C}-\mathrm{H}) \quad \sigma$-type donation, as displayed by model complex 3 (Scheme 1d), we would expect at least a subtle elongation of the bridging $\mathrm{C}-\mathrm{H}$ bond. Indeed, 2 displays a $\mathrm{v}\left(\mathrm{C}-\mathrm{H}_{\text {'ago }}\right)$ stretching frequency at $2805 \mathrm{~cm}^{-1}\left[2878 \mathrm{~cm}^{-1}\right]$ which is clearly shifted to lower frequencies with respect to the $v(\mathrm{C}-\mathrm{H}$ ") $)$ stretching mode of $2864 \mathrm{~cm}^{-1}$ [2917 $\left.\mathrm{cm}^{-1}\right]$ (Figure 2) of the non-coordinating methylene hydrogen atom of the same methylene group (Scheme 2). Note, that theoretical values will be specified in square brackets in the following. Utilizing McKean's empirical correlation, which links $r(\mathrm{C}-\mathrm{H})$ bond lengths to isolated $v_{\text {is }}(\mathrm{C}-\mathrm{H})$ stretching frequencies, predicts a slight activation of the $\mathrm{C}-\mathrm{H}^{\prime}{ }_{\text {ago }}$ bond $\left(r\left(\mathrm{C}-\mathrm{H}^{\prime}{ }^{\prime}{ }_{\text {gao }}\right)=1.111\right.$ $[1.108] \AA)$ in comparison to its non-agostic reference moiety $\left.\left(r\left(\mathrm{C}-\mathrm{H}^{\prime}\right)=1.105[1.104] \AA\right)\right)^{[14 \mathrm{a}, \mathrm{b}]}$ Hence, the bridging $\mathrm{M} \bullet \bullet \mathrm{H}-\mathrm{C}$ moiety of 2 displays a minute, but noticeable $\mathrm{C}-\mathrm{H}$ bond elongation which supports the presence of weak but attractive $M\left(\mathrm{~d}_{\mathrm{z}}{ }^{2}\right) \leftarrow \sigma(\mathrm{C}$ $\mathrm{H})$ interaction in $\mathbf{2}$. Also in case of our agostic benchmark system $\mathbf{1}$ the observed $\left(2704 \mathrm{~cm}^{-1}\right)$ and calculated $\left(2709 \mathrm{~cm}^{-1}\right) \quad v(\mathrm{C}-\mathrm{H})$ stretching modes of the Mo $\bullet \cdot \mathrm{H}-\mathrm{C}$ moieties are in agreement with a subtle $\mathrm{C}-\mathrm{H}$ bond activation. Indeed, the theoretically predicted $\mathrm{C}-\mathrm{H}_{\text {ago }}$ bond length of $1.128 \AA$ is slightly longer than the noncoordinating C-H' reference moiety (1.104 $\AA$ ). Hence, the observed $v\left(\mathrm{C}-\mathrm{H}^{\prime}{ }_{\text {ago }}\right)$ stretching modes in the bridging $\mathrm{C}-\mathrm{H} \cdots \cdot M$ moieties of $\mathbf{1}$ and 2 fall into the typical range of complexes displaying weak agostic interactions; e.g. in the $\beta$-agostic complexes $\mathrm{EtTiCl}_{3}$ (dmpe) (4, where dmpe $\left.=\mathrm{Me}_{2} \mathrm{PCH}_{2} \mathrm{CH}_{2} \mathrm{PMe}_{2}\right)\left(v\left(\mathrm{C}-\mathrm{H}_{\mathrm{ago}}\right)=2585 \mathrm{~cm}^{-1}\right.$; $\left.r\left(\mathrm{C}-\mathrm{H}_{\mathrm{ago}}\right)=1.131 \AA\right)^{[14 \mathrm{c}]}$ and $\left[\mathrm{CpTi}\left(\mathrm{iPr}_{2} \mathrm{~N}\right) \mathrm{Cl}_{2}\right](5)\left(\mathrm{v}\left(\mathrm{C}-\mathrm{H}_{\mathrm{ago}}\right)=2716\right.$ $\left.\mathrm{cm}^{-1} ; r\left(\mathrm{C}-\mathrm{H}_{\mathrm{ago}}\right)=1.120 \AA\right){ }^{[15]}$

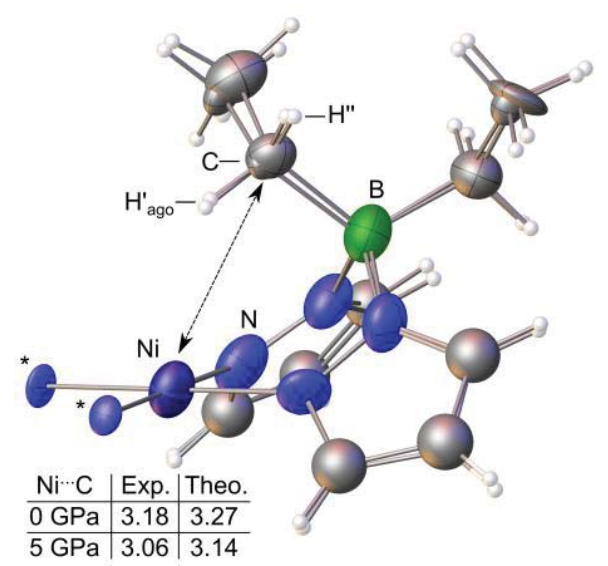

Figure 1. Overlay of structural fragments of 2 obtained by experimental X-ray diffraction studies at 0.0 and $5 \mathrm{GPa}$ pressure using a diamond anvil cell (DAC); $50 \%$ ellipsoids. For two of the nitrogen atoms (marked by stars) only the thermal ellipsoids at $5 \mathrm{GPa}$ were drawn to illustrate the significant reduction of thermal motion in 2 at elevated pressures. Values of the $\mathrm{Ni} \cdots \mathrm{C}$ bond distances are given in $\AA$.

To gain an even deeper insight into the nature of these subtle $\mathrm{d}^{8}-\mathrm{M} \bullet \cdot \mathrm{H}-\mathrm{C}$ interactions we propose to analyze directly the chemical response of these $\mathrm{d}^{8}-\mathrm{M} \cdot \cdots \mathrm{H}-\mathrm{C}$ moieties upon shortening the respective $M \bullet \bullet H$ distances. Such concept can be experimentally accomplished by combined X-ray diffraction (Figure 1) and IR spectroscopic (Figure 2) studies at various pressures. Figure 1 reveals that the $M \cdots \mathrm{C}$ contacts between the metal and the coordinating methylene groups in $\mathbf{2}$ becomes significantly shortened with increasing pressure: $r(M \bullet \bullet C)=3.18$ [3.27] $\AA$ and 3.06 [3.14] $\AA$ at 0 and $5 \mathrm{GPa}$, respectively. Periodic DFT calculations ${ }^{[10 b]}$ also reveal that the respective $M \bullet \cdot \mathrm{H}_{\text {ago }}^{\prime}$ distances are shortened upon increasing pressure (about $0.1 \AA$ at $5 \mathrm{GPa}: r(M \bullet \bullet \mathrm{H})=2.531 \AA$ and $2.431 \AA$ at 0 and $5 \mathrm{GPa}$, respectively). To study the pressure induced effect on the individual C-H bonds we also recorded IR spectra at approximately the same pressures as employed for the $\mathrm{X}$-ray studies. Figure 2 clearly demonstrates that all $v(\mathrm{C}-\mathrm{H})$ stretching modes of the pyrazolyl and ethyl groups in $\mathbf{2}$ are shifted to higher frequencies (blue shifts) - except for the $r\left(\mathrm{C}-\mathrm{H}^{\prime}\right.$ ago $)$ modes of the agostic $\mathrm{Ni} \cdot \bullet \mathrm{H}-\mathrm{C}$ moieties - at increased pressure. This is in line with the theoretical predictions which suggest that all C-H bonds of $\mathbf{2}$ display shorter lengths at elevated pressures, except for the agostic bonds: e.g. $r(\mathrm{C}-\mathrm{H}$ ') bond shrinks significantly by $0.09 \AA$ while the bond lengths of the agostic $\mathrm{C}-\mathrm{H}$ ' moieties remain rather constant between 0.0 and $5.0 \mathrm{GPa})$. Accordingly, the corresponding $v\left(\mathrm{C}-\mathrm{H}^{\prime}{ }_{\text {ago }}\right)$ mode does not show any significant pressure-dependency while the corresponding $v(\mathrm{C}-\mathrm{H}$ ') mode and all other $v(\mathrm{C}-\mathrm{H})$ modes of $\mathbf{2}$ shift to higher frequencies (blue shifted). The expected pressure-induced shortening of the $\mathrm{C}-\mathrm{H}$ bonds in the agostic $\mathrm{Ni} \bullet \cdot \mathrm{H}-\mathrm{C}$ moieties of $\mathbf{2}$ appears therefore to be equally balanced and compensated for by the increasing bond activation/elongation under pressure. Hence, shortening of the $\mathrm{Ni} \cdot \bullet \mathrm{H}$ bond distance in the agostic $\mathrm{C}-\mathrm{H}$ groups activates the bridging $\mathrm{C}-\mathrm{H}^{\prime}$ ago in line with the attractive nature of these $\mathrm{Ni} \bullet \bullet \mathrm{H}-\mathrm{C}$ bonds and their classification as $M\left(\mathrm{~d}_{\mathrm{z}}{ }^{2}\right) \leftarrow \sigma(\mathrm{C}-\mathrm{H})$ $\sigma$-type agostic interactions. In the case where this type of interactions is more pronounced and/or further enhanced (e.g. by $M\left(\mathrm{~d}_{\mathrm{xz}}, \mathrm{yz}\right) \rightarrow \sigma^{*}(\mathrm{C}-\mathrm{H})$ back donation) one should expect even a red 
shift of the C-H' ago frequencies. This is indeed the case for our agostic benchmark system $\mathbf{1}$, where the $\mathrm{C}-\mathrm{H}$ ' ago frequencies shift from 2704 to $2670 \mathrm{~cm}^{-1}$ by an increase of pressure from 0.0 to 7.4 GPa.

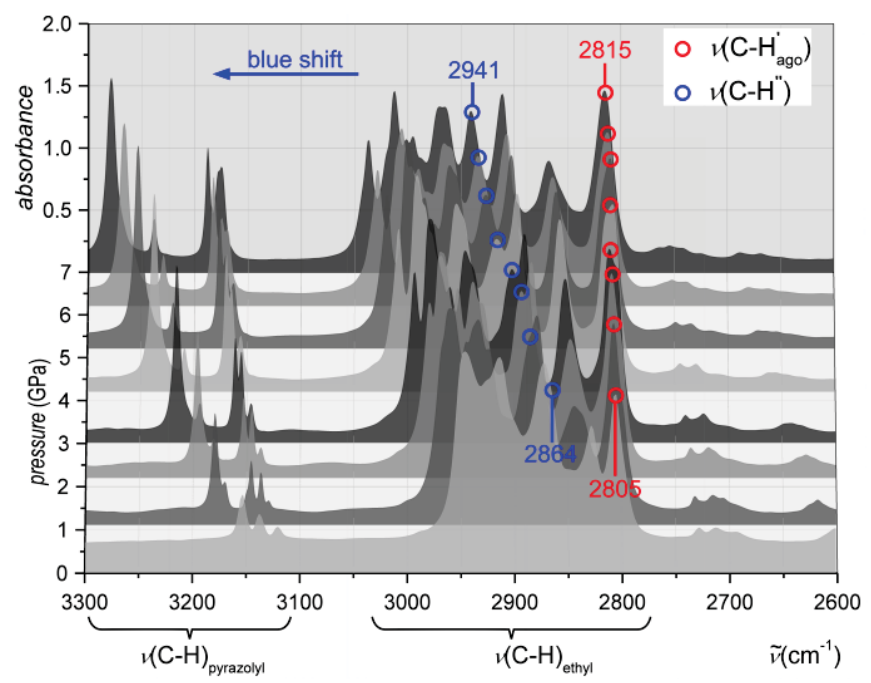

Figure 2. Pressure-dependency of the $v(\mathrm{C}-\mathrm{H})$ stretching modes of the pyrazolyl and ethyl groups in 2. Note that all these stretching modes display a blue shift with increasing pressure but the agostic $v\left(\mathrm{C}-\mathrm{H}_{\text {'ago }}\right)$ mode of the metal-coordinated $\mathrm{Ni} \cdots \mathrm{H}_{\text {ago }} \mathrm{C}$ moieties. This clearly signals the bonding character of these $\mathrm{Ni} \bullet \bullet \mathrm{H}^{\prime}$ ago- $\mathrm{C}$ interactions in $\mathbf{2}$.

However, to characterize the nature of these agostic Ni $\bullet \bullet \mathrm{H}_{\text {ago }}{ }^{\prime} \mathrm{C}$ interactions in 2 in terms of a $M\left(\mathrm{~d}_{\mathrm{z}}{ }^{2}\right) \leftarrow \sigma(\mathrm{C}-\mathrm{H}) \sigma$-type donation process in our model system we need to clarify whether the $\mathrm{Ni}\left(\mathrm{d}_{\mathrm{z}}{ }^{2}\right)$ orbital can be considered as vacant or at least as a partially depleted acceptor orbital (Scheme 1d). Indeed, analysis of the negative Laplacian of the experimental charge density distribution, $L(\mathbf{r})=-$ $\nabla^{2} \rho(\mathbf{r})$, in the valence shell of the metal atom of $\mathbf{2}$ clearly reveals the presence of a local charge depletion zone (denoted "CD" in Figure 3c) in axial ( $z$ ) direction (Figure 4c). This $L(\mathbf{r})$ feature is in conformity with a partially vacant $\mathrm{Ni}\left(\mathrm{d}_{\mathrm{z}}{ }^{2}\right)$ orbital since the Laplacian is a well-established and experimentally accessible indicator to map regions of local charge concentration $\left(L(\mathbf{r})>0 \mathrm{e}^{-5}\right) .{ }^{[16]}$ The bond path between the $\sigma$-agostic hydrogen atoms and the metal center in 2 thus represents an attractive donor interaction in the charge density picture (Figure 3). We note, that an endocyclically curved $M \bullet \bullet H-C$ bond path topology has been also experimentally observed in case of $\beta$-agostic $d^{0}$ transition metal alkyls (e.g. 4, Figure 4a) and signals the electron-deficient nature of the respective $\mathrm{M} \cdot \bullet^{\circ} \mathrm{H}^{\prime}$ ago- $\mathrm{C}$ moieties in 2 and 4. ${ }^{[17]}$ Indeed, in both cases the $M(\mathrm{~d}) \leftarrow \sigma(\mathrm{C}-\mathrm{H}) \sigma$-type donation component is rather weak as witnessed by the minute density accumulation in the $M \cdots \cdot \mathrm{H}$ bonding domain (Figure 3). Accordingly, the electron density accumulation at the $M \bullet \bullet \mathrm{H}^{\prime}$ ago bond critical point (BCP) in 2 is rather small $\left(\rho(\mathbf{r})_{\exp }=0.082(4) ; \rho(\mathbf{r})_{\text {calc }}=[0.10]\right.$ $\mathrm{e} / \AA^{-3}$ ) and a BCP is even lacking in case of $4 .^{[18]}$

The weakness of the agostic interaction in $\mathbf{2}$ also becomes obvious by direct comparison with the $\mathrm{d}^{8}-\mathrm{Ni}$ complex $\left[(\mathrm{DCpH}) \mathrm{Ni}\left(\mathrm{d}^{\mathrm{t}} \mathrm{bpe}\right)\right]^{+}\left[\mathrm{BF}_{4}\right](\mathbf{6} \mathrm{DCpH}=\text { dicyclopentenyl })^{[31]}$ which is our benchmark system for compounds displaying strong agostic interactions (Figure 4b): in that case the $\mathrm{Ni} \bullet \bullet \mathrm{H}$ BCP is well pronounced $\left(\rho(\mathbf{r})=0.553(4) \mathrm{e} / \AA^{-3}\right)$, the Ni-H'ago bond distance (1.671(9) $\AA$ ) is significantly shorter than in 2 (2.376 $\AA$ ) and the C-H activation is large $(\mathrm{C}-\mathrm{H}=1.20(1) \AA) \cdot{ }^{[19]}$ Apparently, complexes 2, 4 and 6 represent benchmark systems for three different scenarios of agostic interations (Figure 4).

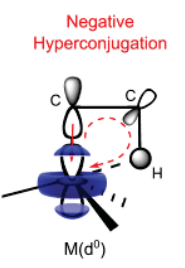

a

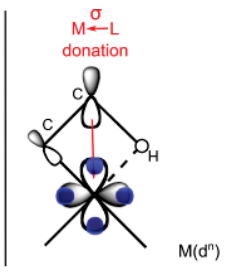

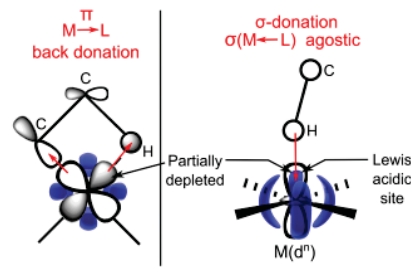

Figure 4. Three different types of agostic interactions in $d^{0}$ and $d^{n}$ transition metal complexes and their relevant molecular orbital contribution which are directly linked with the $L(\mathbf{r})$ pattern (blue envelope maps) at the central transition metal atoms (see also ref 17b).

In the final step of our analysis we will focus on the NMR properties of $\mathbf{1}$ and $\mathbf{2}$ which display in ${ }^{1} \mathrm{H}$ NMR experiments rather different chemical shifts of the agostic protons (Scheme 2).The agostic protons in $\mathbf{1}$ are clearly shifted upfield $\left(\delta\left({ }^{1} \mathrm{H}\right)=-5.88 \mathrm{ppm}\right)$ but downfield in $2\left(\delta\left({ }^{1} \mathrm{H}\right)=+6.1 \mathrm{ppm}\right)$. However, the calculations show, that the upfield/downfield shift of these agostic protons is not correlated with their "hydridic" character - as originally proposed by Trofimenko ${ }^{[6 a]}$ and also postulated in the BG model ${ }^{[11]}$ of agostic interactions. The agostic hydrogen atoms in $\mathbf{1}$ and $\mathbf{2}$ display both only small negative atomic charges and thus differ only marginally $\left(Q_{\text {AIM,calc }}=-0.14\right.$ and -0.08 e, respectively $)$. As outlined in greater detail in a recent publication, the chemical shifts of agostic protons in transition metal alkyls rather depend on the polarization pattern of the valence shell density of the metal and/or the topology of the induced current density distributions in magnetic fields than on their "hydridic character". ${ }^{[13 c]}$ In the case of all agostic complexes studied

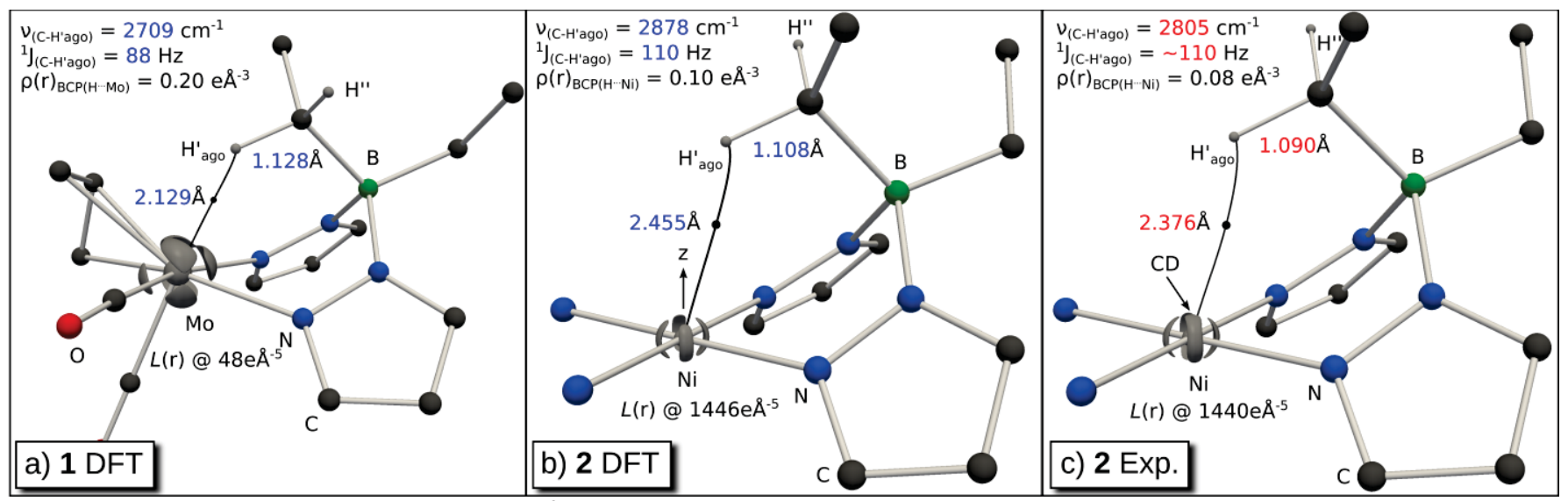

Figure 3. Theoretical and experimental $L(r)=-\nabla^{2} \rho(\boldsymbol{r})$ isocontur surface maps of complexes a) 1 and b,c) 2. Only bond paths between the individual metal and agostic hydrogen $\left(\mathrm{H}^{\prime}\right.$ ago $)$ atoms are drawn. 
so far by topological analyses of the charge and/or current density, pronounced upfield shifts are only observed when agostic C-H moieties are pointing toward a pronounced local Lewis acidic site in the valence shell of the metal atom. ${ }^{[17 b]}$ Indeed, inspection of the Laplacian maps of $\mathbf{1}$ and $\mathbf{2}$ (Figure 3) reveals, that only in case of $\mathbf{1}$ the agostic proton is "intruding" into a pronounced charge depletion zone, which represents a local Lewis acidic center in the charge density picture, or a vacant metal d-orbital in the MO model. A similar topological scenario is observed for the agostic protons in $\mathbf{2}$, however, the axial Lewis acidic sites in the valence shell of the nickel atom are less pronounced relative to the $\mathrm{d}^{4}$ complex $\mathbf{1}$. Furthermore, the chemical shifts in planar $\mathrm{d}^{8}$ complexes are also strongly influenced by the topology of the current density which is dominant in the equatorial plane of square-planar $\mathrm{d}^{8}$ complexes and thus causes a general deshielding of axially coordinating protons. ${ }^{[13 c]}$ Thus, the downfield chemical shift of the agostic proton in $\mathbf{2}$ does not rule out its agostic character. We therefore suggest, not to use the sign of ${ }^{1} \mathrm{H}$ NMR shifts as major criterion to classify $M \cdots \cdot \mathrm{H}-\mathrm{C}$ interactions as attractive (agostic) or repulsive (anagostic). As outlined above combined high pressure IR and diffraction studies provide a more direct insight in the nature of these interactions especially in combination with the analysis of the topology of the charge and current density.

To conclude: We have unequivocally revealed that square-planar $\mathrm{d}^{8}-M L_{4}$ complexes display subtle but noticeable local Lewis acidic sites in axial direction in the valence shell of the metal atom. These sites of local charge depletion provide the electronic prerequisites to establish weakly attractive 3c-2e $M \cdot \bullet \cdot \mathrm{H}-\mathrm{C}$ agostic interactions (Scheme 1d and Figure 4c) which are controlled by the extent of $M\left(\mathrm{~d}_{\mathrm{z}}^{2}\right) \leftarrow \sigma(\mathrm{C}-\mathrm{H})$ donation. We therefore suggest to use more carefully the expression "anagostic interactions" which describes $M \bullet \bullet H-C$ interactions in square-planar $\mathrm{d}^{8}-M L_{4}$ in terms of repulsive 3c-4e interactions. Indeed, the latter bonding concept is based on a purely electrostatic description of $M \bullet \cdot H-C$ interactions in $d^{8}-M L 4$ complexes in terms of crystal field theory and ignores the consequences of strong covalent metal ligand interactions which might induce local Lewis acidic sites in the valence shell of the metal in axial direction.

Received: ((will be filled in by the editorial staff))

Published online on ((will be filled in by the editorial staff))

Keywords: charge density - bond activation - agostic interactions high pressure

[1] a) W. I. Sundquist, D. P. Bancroft, S. J. Lippard, J. Am. Chem. Soc. 1990, 112, 1590-1596; b) H. M. Echols, D. Dennis, Acta Cryst. 1976, B32, 1627-1630; c) J. Y. Saillard, R. Hoffmann, J. Am. Chem. Soc. 1984, 106, 2006-2026.

[2] a) L. Brammer, J. M. Charnock, P. L. Goggin, R. J. Goodfellow, T. F. Koetzle, A. G. Orpen, Chem. Commun. 1987, 443-445; b) L. Brammer, D. Zhao, F. T. Lapido, J. Braddock-Wilking, Acta Cryst. 1995, B51, 632-640; c) L. Brammer, Dalton Trans. 2003, 3145-3157.

[3] a) M. Bortolin, U. E. Bucher, H. Ruegger, L. M. Venanzi, A. Albinati, F. Lianza, S. Trofimenko, Organometallics 1992, 11, 2514-2521; b) Y. Zhang, J. C. Lewis, R. G. Bergman, J. A. Ellman, E. Oldfield, Organometallics 2006, 25, 35153519.
[4] a) C. G. Anklin, P. S. Pregosin, Magn. Reson. Chem. 1985, 23, 671-675; b) A. Albinati, C. G. Anklin, F. Ganazzoli, H. Ruegg, P. S. Pregosin, Inorg. Chem. 1987, 26, 503-508.

[5] S. Trofimenko, J. Am. Chem. Soc. 1967, 89, 6288-6294.

[6] a) S. Trofimenko, J. Am. Chem. Soc. 1968, 90, 4754-4755. b) S. Trofimenko also specified a second frequency at $2664 \mathrm{~cm}^{-}$ ${ }^{1}$ which, represents a combination mode.

[7] a) Complex 2 was synthesized according to modified literature methods (see ref 5 and the Supporting Information). The high-resolution data set for the $100 \mathrm{~K}$ data provided $98.9 \%$ completeness in $2.48^{\circ}<2 \theta<54.10^{\circ}\left(\sin \theta_{\max } / \lambda=1.14 \AA^{-1}\right)$. The deformation density was described by a multipole model (ref 7b) with spherical harmonics multiplied with Slater-type radial functions with energy-optimized exponents (ref 7c,d) using the XD program (see S3). CCDC 1030979 and 10311861031191 contain the supplementary crystallographic data for this paper. These data can be obtained free of charge from The Cambridge Crystallographic Data Centre via www.ccdc.cam.ac.uk/data_request/cif. b) N. K. Hansen, P. Coppens, Acta Cryst. 1978, A34, 909-921. c) Z. Su, P. Coppens, Acta Cryst. 1998, A54, 646-652. d) E. Clementi, D. L. Raimondi, J. Chem. Phys. 1963, 38, 2686-2689. e) The HP single crystal diffraction experiments were conducted with a Merrill Bassett DAC with $0.5 \mathrm{~mm}$ culet conical diamond anvils. A crystal was placed into a pre-intended stainless steel gasket and filled with a 4:1 mixture of methanol ethanol as pressure-transmitting medium. f) Pressure-dependent transmittance measurements were conducted in the frequency range of 550-8000 $\mathrm{cm}^{-1}$ using a Bruker IRscope II coupled to a Bruker IFS 66v/S FT-IR spectrometer. A clamp diamond anvil cell was used with a pre-intended $\mathrm{CuBe}$ gasket and nitrogen as hydrostatic pressure-transmitting medium.

[8] F. A. Cotton, R. L. Luck, Inorg. Chem. 1989, 28, 3210-3213.

[9] F. A. Cotton, A. G. Stanislowski, J. Am. Chem. Soc. 1974, 96, 5074-5082.

[10] (a) Molecular DFT calculations were performed with ADF using the BP86 or PBE0-functional, the ZORA for the description of scalar relativistic effects and the TZ2P or JCPL basis set as implemented in ADF. (b) The periodic B3LYP/ DGDZVP DFT calculations used the CRYSTAL09 code; see the Supporting Information for further details.

[11] a) M. Brookhart, M. L. H. Green, J. Organomet. Chem. 1983, 250, 395-408; b) M. Brookhart, M. L. H. Green, L. L. Wong, Prog. Inorg. Chem. 1988, 36, 1-124.

[12] H. M. Echols, D. Dennis, Acta Cryst. 1974, B30, 2173-2176.

[13] a) W. Yao, O. Eisenstein, R. H. Crabtree, Inorg. Chim. Acta 1997, 254, 105-111; b) M. Brookhart, M. L. H. Green, G. Parkin, Proc. Natl. Acad. Sci. U. S. A. 2007, 104, 6908-6914; c) J. E. Barquera-Lozada, A. Obenhuber, C. Hauf, W. Scherer, J. Phys. Chem. A 2013, 117, 4304-4315.

[14] a) D. C. McKean, Chem. Soc. Rev. 1978, 7, 399-422; b) D. C. McKean, J. Mol. Struct. 1984, 113, 251 - 266; c) D. C. McKean, G. S. McGrady, A. J. Downs, W. Scherer, A. Haaland, Phys. Chem. Chem. Phys. 2001, 3, 2781-2794.

[15] W. Scherer, D. J. Wolstenholme, V. Herz, G. Eickerling, A. Bruck, P. Benndorf, P. W. Roesky, Angew. Chem. Int. Ed. 2010, 49, 2242-2246.

[16] R. F. W. Bader, P. J. MacDougall, C. D. H. Lau, J. Am. Chem. Soc. 1984, 106, 1594 - 1605.

[17] a) W. Scherer, G. S. McGrady, Angew. Chem. Int. Ed. 2004, 43, 1782-1806; b) W. Scherer, V. Herz, C. Hauf, Struct. Bond. 2012, 146, 159-207.

[18] W. Scherer, P. Sirsch, D. Shorokhov, M. Tafipolsky, G. S. McGrady, E. Gullo, Chem. Eur. J. 2003, 9, 6057-6070.

[19] W. Scherer, V. Herz, A. Bruck, C. Hauf, F. Reiner, S. Altmannshofer, D. Leusser, D. Stalke, Angew. Chem. Int. Ed. 2011, 50, 2845-2849. 